areas of necrosis below the knee. As a result of hyperbaric oxygenation the limbs were saved ending with a partial foot amputation only.

\section{Discussion}

The patients reported here presented with the rare and most severe variant of disseminated intravascular clotting: sudden occlusion of multiple peripheral arterioles by massive microthrombosis. This phenomenon has been variously described as purpura fulminans or purpura gangrenosa ${ }^{1}$ and has its onset after various infections. Massive areas of haemorrhage in the skin, usually of the arms and legs, may progress to extensive gangrene. There is, however, a wide marginal zone of hypoxia due to partial arteriolar occlusion which may benefit by hyperbaric oxygenation treatment.

The extensive use of this treatment in humans is restricted by the development of bronchopulmonary dysplasia and convulsions. ${ }^{2}$ The development of oxygen toxicity may be delayed by interposing regular, intermittent periods of normal oxygen levels without concurrently reducing the beneficial effects. $^{3}$

Over the past 20 years hyperbaric oxygenation has become an important treatment in a wide variety of anoxic conditions. ${ }^{4}$ We could find, however, only two reports of infants with purpura fulminans treated with this. ${ }^{5}{ }^{6}$ Both had a much milder course with no loss of limbs. In those cases the authors felt that spontaneous recovery might have occurred anyway, and the treatment mainly served to shorten the duration of the disease.

In the patients presented here, however, we believe that hyperbaric oxygenation had a major influence in reducing the areas doomed for amputation. The good clinical results suggest that hyperbaric oxygenation may have a major treatment application in this serious condition.

\footnotetext{
References

1 Urbaniak JR, O'Neil MT, Meyer LC. Purpura fulminans. J Bone Joint Surg 1973;55:69-77.

2 Lambertson CJ. Effects of oxygen at high partial pressure. In: Haffner FG, ed. Handbook of physiology of respiration, vol 2. Baltimore: Williams and Wilkins, 1965:1027.

${ }^{3}$ Miller JH, Mendoza SA. Protection against the toxic effects of hyperbaric oxygen by intermittent exposure to reduced oxygen pressures. Pediatr Res 1978;12:283-7.

${ }^{4}$ Gunby P. Evaluation continues of $\mathrm{HBO}$ clinical uses. JAMA 1981;246:1059-64.

5 Waddell WB, Saltzman HA, Fuson RL, Harrison J. Purpura gangrenosa treated with hyperbaric oxygenation. JAMA 1965; 191:971-4.

6 Kuzemko JA, Loder RE. Purpura fulminans treated with hyperbaric oxygen. Br Med J 1970;iv:157.
}

Correspondence to Dr A Benderly, Department of Paediatrics A, Rambam Medical Center, Haifa 35254, Israel.

Received 3 January 1985

\title{
Treatment of respiratory papillomatosis with adenine arabinoside
}

\author{
W A HENDRICKSE, B C IRWIN, R J LEVINSKY, C M BAILEY, G TYMM, \\ AND J N G EVANS
}

Hospital for Sick Children, Great Ormond Street, and Institute of Child Health, London

SUMMARY Nine children with respiratory papillomatosis have been treated with adenine arabinoside with limited success. No long term benefit was obtained in six, and although resolution was achieved in one and probably two others, this could not be attributed confidently to treatment.

Respiratory papillomatosis (or laryngeal papillomatosis) are histologically benign tumours that usually arise in the larynx but may spread throughout the respiratory tract. Consequently, the disease may be life threatening if the airway is impaired. The mainstay of management is surgical but if the disease is widespread complete removal may be impossible. A viral aetiology has long been suspected and recently evidence has been obtained of an association between respiratory papillomata and deoxyribonucleic acid (DNA) containing human papilloma virus. ${ }^{12}$ Treatment with an anti-DNA virus agent, therefore, seems rational. ${ }^{3}$ Adenine arabinoside is an established anti-DNA viral agent but there have been no published reports giving detailed results of its use in treating this condition.

We therefore reviewed the case records of all 
children with respiratory papillomatosis who have been treated with adenine arabinoside at the Hospital for Sick Children.

\section{Results}

Since 1979 , nine children have been treated with adenine arabinoside (Table). They represent the most severe cases and all had required tracheostomy. Patient selection was not random. Adenine arabinoside (10 to $20 \mathrm{mg} / \mathrm{kg}$ per day) was administered by slow intravenous infusion for between five and 14 days, and one patient (case 8 ) received the monophosphate derivative $(40 \mathrm{mg} / \mathrm{kg} /$ day $)$ for six weeks. Treatment was generally well tolerated but one child exhibited a transient rise in liver enzymes and another developed a mild urticarial eruption.

In eight patients (cases 1 and 3-9) papilloma initially seemed to resolve becoming paler and smaller. In none of the children did they resolve completely, however, and in every one new lesions subsequently occurred. All required many therapeutic endoscopies, which did not alter in frequency after treatment with adenine arabinoside. Three patients eventually remitted.

Cases 1, 3, and 4. The disease cleared five to nine months after adenine arabinoside treatment in these patients, but the drug treatment was combined with continued intensive surgical removal in each. In one patient (case 3 ) only the larynx was affected.

Cases 2 and 5-9. Five of these patients showed limited regression immediately after treatment but there was no permanent change in disease. Nine courses of treatment were given to one patient (case 5 ) and this may have enabled more radical surgery than might otherwise have been possible for her extensive disease. One patient (case 6) eventually required laryngectomy, and details of this case have been published. ${ }^{4}$

\section{Discussion}

An objective analysis of the results has not sustained our initial enthusiasm for the use of adenine arabinoside in treating children with respiratory papillomatosis. ${ }^{5}$ In eight of the nine children papilloma seemed to improve with treatment but six obtained no long term benefit. Resolution of disease in the remaining three cannot be attributed with any confidence to this treatment. In these three patients treatment was combined with surgical removal and new lesions continued to occur over a number of months. It is possible that adenine arabinoside enables more radical surgery with a lower risk of reseeding the bronchial tree. The fluctuant nature of this disease, however, makes analysis of any treatment difficult; in the past 10 years, out of 14 other patients, we have achieved resolution of disease in six by surgery alone and extralaryngeal spread had occurred in two of them.

Adenine arabinoside, although a relatively safe drug, seems to have a limited role in treatment. Reports of success with interferon hold out greater hope for the future. ${ }^{6}$ We have recently treated two of the patients included in this study with exogenous $\alpha$ leukocyte interferon, and have observed an

Table Patients with respiratory papillomatosis treated with adenine arabinoside (AraA)

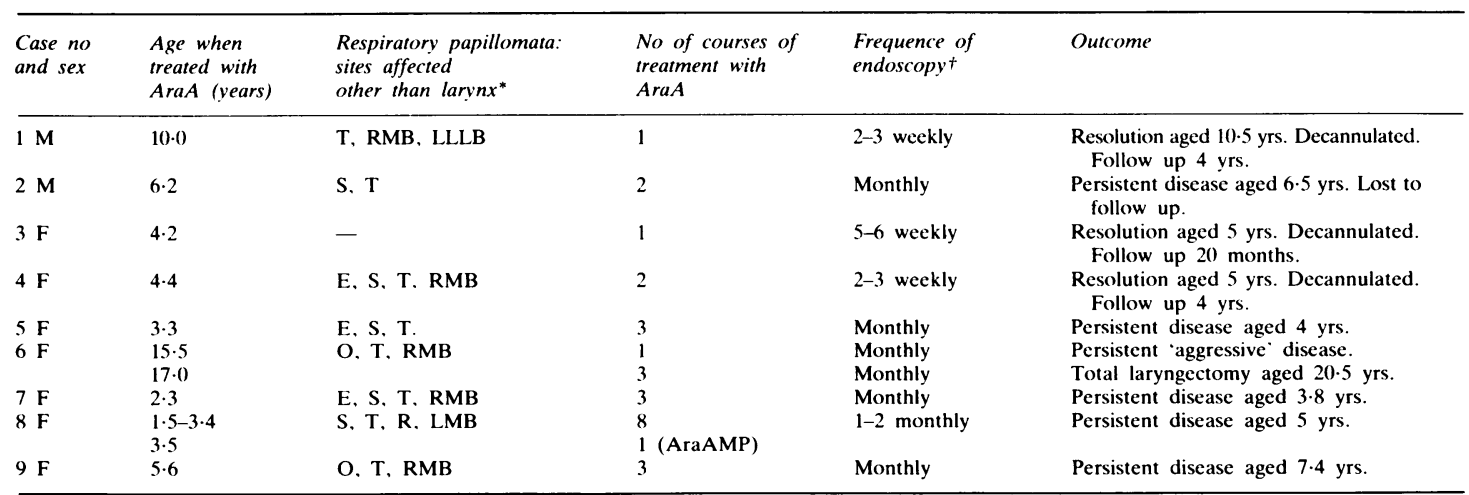

$\mathrm{T}=$ Trachea; $\mathrm{RMB}=$ Right main bronchus; $\mathrm{R} / \mathrm{LLB}=$ right-left lower lobe bronchus; AraAMP=adenine arabinoside monophosphate; $\mathrm{S}=$ supraglottis; $\mathrm{E}=$ epiglottis; $\mathrm{O}=$ oropharynx.

${ }^{*}$ Larynx affected in all patients.

tFrequency did not alter after treatment with AraA. 
appreciable improvement. This is an uncommon disease, however, and any further advances seem likely to come only from multicentre studies.

\footnotetext{
References

${ }^{1}$ Steinberg BM, Topp WC, Schneider PS, Abramson AL. Laryngeal papillomavirus infection during clinical remission. $N$ Engl J Med 1983;308:1261-4.

2 Lancaster W, Jenson AB. Evidence for papillomavirus genusspecific antigens and DNA in laryngeal papillomas. Intervirology 1981;15:204-12.

${ }^{3}$ Multiple papillomas of the larynx in children. [Editorial]. Lancet $1981 ; \mathrm{i}: 367-8$.
}

${ }^{4}$ Robbins KT, Howard D. Multiple laryngeal papillomatosis requiring laryngectomy. Arch Otolaryngol 1983;109:765-9.

5 Pritchard J, Eggerding C, Evans JNG, et al. Treatment of laryngeal papillomatosis. Lancet 1980 ;ii: 1383 .

6 Geopfert H, Gutterman JU, Dichtel WJ, Sessions RB, Cangir A, Sulek M. Leukocyte interferon in patients with juvenile laryngeal papillomatosis. Ann Otol Rhinol Laryngol 1982;91:431-6.

Correspondence to Dr W A Hendrickse, Department of Immunology, Institute of Child Health, 30 Guilford Street, London WCIN 1EH.

Received 8 November 1984

\title{
International trends in hospital admission rates for asthma
}

\author{
E A MITCHELL
}

Department of Health, South Auckland Health District, New Zealand

SUMMARY Trends in annual hospital admission rates for asthma in the 0 to 14 year age group were examined in New Zealand, England and Wales, the United States, Canada, and Australia. There has been a striking increase in hospital admissions for asthma in children in all these countries since the mid 1960s.

Hospital admission rates for asthma have increased noticeably since the mid 1960 s in New Zealand. ${ }^{1}$ In the 0 to 14 year age group admissions have increased 10 fold in 15 years (63 per 100000 in 1966 to 629 per 100000 in 1981). An increase in hospital admissions for asthma in children in England and Wales has also been noted. ${ }^{2}$ As part of an investigation into possible explanations for this increase, trends in annual hospital admission rates for asthma in New Zealand children were compared with those of other countries.

\section{Methods}

Hospital admission data for asthma (ICD Code 493) for the 0 to 14 year age group were obtained for New Zealand, Canada, the United States, England and Wales, and Australia. Strictly speaking hospital admissions are discharges from or deaths in hospital for all countries examined, except the United States where the data refer to discharges from hospital. This difference is unimportant as asthma deaths in hospital are rare events compared with asthma admissions. The data from New Zealand and Canada are based on all admissions. The data from England and Wales are based on a $10 \%$ sample of inpatient records from National Health Service hospitals. The United States data are based on a sample of short stay general and specialty hospitals, and in 1980 the sample was approximately $0.5 \%$ of total admissions. Australia does not collect national statistics on hospital admissions, however, these statistics are collected from all hospitals in the states of Queensland and Tasmania, and are reported separately. The data were available for New Zealand from 1952 to 1981, for Canada from 1960 to 1978, for the United States from 1965 to 1980, for England and Wales from 1957 to 1981, for Tasmania from 1969 to 1980, and for Queensland from 1963 to 1980. As changes in the population may have occurred over the time period, the data were expressed as admission rates per 100000 population of age 0 to 14 years.

\section{Results}

The Figure shows the annual rate of hospital admission for the 0 to 14 year age group for these countries. All countries have shown a striking increase with time, the increase seeming to begin in the mid to late 1960s. In New Zealand the hospital admission rate for the 0 to 14 age group has increased 10 fold in 15 years. England and Wales have shown a sixfold increase, the United States a 